\title{
Evaluation of perinatal outcome in women presented with first trimester vaginal bleeding: our experience
}

\author{
Priyanka Rai $^{1 *}$, Girija Kumari², Kalpana Kumari ${ }^{3}$, Deepshikha Jaiswal ${ }^{4}$
}

\begin{abstract}
${ }^{1}$ Lecturer, ${ }^{3}$ Associate Professor, ${ }^{4}$ Junior Resident, Department of Obstetrics and Gynecology, Uttar Pradesh University of Medical Sciences, Saifai, Uttar Pradesh, India

${ }^{2}$ Assistant Professor, Department of Obstetrics and Gynecology, Anugrah Narayan Magadh Medical College and Hospital, Gaya, Bihar, India
\end{abstract}

Received: 17 January 2017

Revised: 25 January 2017

Accepted: 30 January 2017

\section{*Correspondence: \\ Dr. Priyanka Rai, \\ E-mail: drpriyanka242@gmail.com}

Copyright: ( ) the author(s), publisher and licensee Medip Academy. This is an open-access article distributed under the terms of the Creative Commons Attribution Non-Commercial License, which permits unrestricted non-commercial use, distribution, and reproduction in any medium, provided the original work is properly cited.

\begin{abstract}
Background: First trimester vaginal bleeding (FTVB) plays a role in occurrence of late pregnancy complications in both mother and infant. Late pregnancy outcomes in mothers and infants are the main concerns for the obstetricians. The purpose of this study was to assess the perinatal outcome of pregnancies complicated by first trimester vaginal bleeding.

Methods: The present study included total 100 singleton pregnant women with history of FTVB whose pregnancy was confirmed chemically. Patients were closely observed and follow up done 2 weekly upto 36 weeks and weekly after that. Late pregnancy outcomes such as gestational hypertension, pre eclampsia, placental abruption, preterm delivery and pre mature rupture of membranes in the mothers and low birth weight, intrauterine growth ristriction, apgar score after 1 and 5 minutes, and NICU admission in new born were calculated.

Results: Incidence of PROM, gestational hypertension and placental abruption is more in women with FTVB. However there infant had higher rate of IUGR and LBW. Apgar score after 1 and 5 minutes were less than 5 and admission to NICU too.

Conclusions: FTVB is an important factor to predict both the maternal and fetal outcomes in late pregnancy. It is therefore important to evaluate and consider these pregnancies as high risk group and provide careful antenatal care.
\end{abstract}

Keywords: FTVB, Preterm labour pain, Pregnancy outcome

\section{INTRODUCTION}

First trimester bleeding per vaginum is one of the most common obstetric problems, complicating 16- $25 \%$ of all pregnancies. ${ }^{1}$ Vaginal bleeding in the first trimester of pregnancy is associated with ectopic pregnancy, abortion (threatened, inevitable, incomplete or complete), implantation of preganancy, hydatiform mole and cervical pathology. Threatened abortion is presumed when a bloody vaginal discharge or bleeding appears through a closed cervical os during first half of pregnancy. Approximately half of these pregnancies will abort, although the risk is substantially lower if foetal cardiac activity is visualised. Vaginal bleeding is associated with a twofold increased risk of other complications during that pregnancy., ${ }^{4,5}$ There is increased risk of suboptimal pregnancy outcome in the form of preterm deliveries, low birth weight and unexplained intrauterine death in these cases. ${ }^{6-14}$ The present study aimed to evaluate the perinatal outcomes in a pregnant women with a history of vaginal bleeding in the first trimester of their pregnancy. 


\section{METHODS}

We examined 100 singleton pregnant women with first trimester bleeding per vaginum, who came to the Department of Obstretics and Gynaecology in our institute during 2013-15 and whose pregnancy was confirmed by urine pregnancy test. After taking an informed consent, patient were kept under surveillance until delivery and the consequences of pregnancy were evaluated by close observation and follow up.

\section{Inclusion criteria}

Singleton pregnancies complicating with FTVB $(<14$ weeks) with positive cardiac activity detected with ultrasound.

\section{Exclusion criteria}

- Hydatiform mole

- Cervical pathology

- Women with chronic medical complications including diabetes, hypertension, cardiac disease, hepatic disease

- Bleeding disorders

- Any evidence of foetal anomaly

- Women with history of infertility

- Multiple pregnancies

Follow up were done every 2 weekly upto 36 weeks and weekly after that. Foetal growth was monitored closely by clinical examination and repeat ultrasound scan at 6- 8 weeks interval. Late pregnancy complications were evaluated in two categories of maternal and foetal complications. Maternal complications included PROM, PTLP, APH, gestational hypertension, preeclamsia. Foetal complications included LBW, IUGR, APGAR score 1 after 5 minutes of delivery, Live birth or Pregnancy loss.

\section{RESULTS}

In present study, 100 cases of FTVB were studied. Majority of patients (70\%) presented with spotting, out of which $62(88.5 \%)$ had a viable pregnancy and only 8 (11.4\%) had abortion. $16(80 \%)$ out of 20 patients with moderate bleeding in first trimester had abortion. All of 10 patients with heavy bleeding per vaginum during first trimester had abortion.

Over all $34 \%$ cases with FTVB were aborted and rest $66 \%$ pregnancies continued beyond 20 weeks of gestation.

Table 1: Age distribution.

\begin{tabular}{|lll|}
\hline Age in years & Number & Percent (\%) \\
\hline$<20$ & 26 & $26 \%$ \\
\hline $21-25$ & 35 & $35 \%$ \\
\hline $26-30$ & 28 & $28 \%$ \\
\hline $31-35$ & 11 & $11 \%$ \\
\hline Total & 100 & $100 \%$ \\
\hline
\end{tabular}

Table 2: Correlation of duration and amount of bleeding with pregnancy outcome.

\begin{tabular}{|lllllll|}
\hline \multirow{2}{*}{ Duration of bleeding $\mathrm{p} / \mathrm{v}(\mathrm{BPV})$} & Spotting & \multicolumn{2}{c}{ Moderate BPV } & \multicolumn{2}{c|}{ Heavy BPV } \\
\cline { 2 - 7 } & Viable & Non viable & Viable & Non viable & Viable & Non viable \\
\hline $1-2$ & 23 & 4 & 3 & 6 & 0 & 4 \\
\hline $3-4$ & 32 & 2 & 1 & 8 & 0 & 1 \\
\hline $5-6$ & 5 & 1 & 0 & 1 & 0 & 3 \\
\hline $7-8$ & 2 & 1 & 0 & 1 & 0 & 2 \\
\hline Total & 62 & 8 & 4 & 16 & 0 & 10 \\
\hline
\end{tabular}

Table 3: Maternal outcome.

\begin{tabular}{|lll|}
\hline $\begin{array}{l}\text { Maternal } \\
\text { complications }\end{array}$ & $\begin{array}{l}\text { Number of } \\
\text { patients }(\mathbf{N}=66)\end{array}$ & $\begin{array}{l}\text { Percent } \\
(\%)\end{array}$ \\
\hline PROM & 24 & $36 \%$ \\
\hline Placental abruption & 6 & $9 \%$ \\
\hline Placenta preavia & 9 & $14 \%$ \\
\hline Preeclampsia & 10 & $15 \%$ \\
\hline No complication & 17 & $26 \%$ \\
\hline Total & 66 & 100 \\
\hline
\end{tabular}

Out of 66 patients, PROM presented in $36 \%$ of cases, placenta previa in $14 \%$, placental abruption in $9 \%$, and
PIH were seen in $15 \%$ cases. $26 \%$ patients had no such maternal complications.

Table 4: Foetal outcome.

\begin{tabular}{|c|c|c|}
\hline Foetal outcome & Number $(\mathrm{N}=66)$ & Percent (\%) \\
\hline Full term & 36 & $55 \%$ \\
\hline Preterm & 16 & $24 \%$ \\
\hline IUGR & 9 & $14 \%$ \\
\hline IUD & 5 & $7 \%$ \\
\hline
\end{tabular}

In foetal outcome $55 \%$ patients delivered full term, $24 \%$ delivered preterm, $14 \%$ had IUGR, and $7 \%$ had IUD. 
$30.6 \%$ new born had NICU admission and 37.8\% had low birth weight (LBW).

\section{DISCUSSION}

First trimester bleeding per vaginum is not only associated with abortion but also with a higher rate of pregnancy complications. The present study shows that women with first trimester bleeding per vaginum and continued beyond 20 weeks of gestation are at increased risk of later complications such as preterm delivery, PROM, lower gestational foetal weight. ${ }^{15-17}$ Because of impaired implantation and inadequate invasion of trophoblasts, spontaneous abortion may occur in early pregnancy while preterm delivery, PPROM, placental ablation and preeclampsia may happen in late period. ${ }^{16,18,19}$

Preterm delivery and PPROM rates were increased in this group of patients because of increased free iron deposits from subchorionic bleeding, hydroxyl radical is catalysed damaging the membrane. ${ }^{17,18}$

The other point in PPROM etiology is the chronic inflammatory reaction within the deciduas and placental membranes which causes rupture of the membranes, decidual thrombosis, ischaemia and necrosis results in vaginal bleeding along with inflammatory response and thrombosis formation. Thrombin is a uterotonic agent and may cause preterm labor during late pregnancies and spontaneous abortion during early weeks of gestation. ${ }^{1}$

Both preterm delivery and PPROM leads to low birth weight. Neonatal intensive care unit admission for low birth weight foetuses were increased because of prematurity complications such as respiratory distress. ${ }^{1,17}$ Bleeding amount and characteristics are related with poor maternal and foetal outcome.

\section{CONCLUSION}

Concluding the result of present study, first trimester bleeding can be a predicting factor for late trimester pregnancy outcome; both maternal and foetal outcomes. It is therefore necessary to consider these pregnancies as a high risk group for which antenatal care should be performed carefully.

Funding: No funding sources Conflict of interest: None declared

Ethical approval: The study was approved by the Institutional Ethics Committee

\section{REFERENCES}

1. Yakıştıran B, Yüce T, Söylemez F. First trimester bleeding and pregnancy outcomes: case-control study. Int J Women Health Reprod Sci. 2016;4(1):47.
2. Corton MM, Leveno K, Bloom S, Hauth J, Rouse D, Spong C. In: Williams obstetrics. 23rd ed. McGraw Hill Professional; 2009: 220-226.

3. Tongsong $\mathrm{T}$, Srisomboon J, Wanapirak C, Sirichotiyakul S, Pongsatha S, Polsrisuthikul T. Pregnancy outcome of threatened abortion with demonstrable fetal cardiac activity: A cohort study. J obstet gynaecol. 1995;21(4):331-5.

4. Ananth CV, Savitz DA. Vaginal bleeding and adverse reproductive outcomes: a meta-analysis. Paediatric Perinat Epidemiol. 1999;8:62-78.

5. Amirkhani Z, Akhlaghdoust M, Abedian M, Salehi GR, Zarbati N, Mogharehabed M, et al. Maternal and perinatal outcomes in pregnant women with first trimester vaginal bleeding. J Fam Reprod Health. 2013;7(2):57-61.

6. Funderburk SJ, Burthrie D. Outcome of pregnancies complicated by early vaginal bleeding. Brit J Obstet Gynaecol. 1980;87:100-5.

7. Berkowitz GS, harlap S, Beck GJ, Freeman DH, Balas M. Early gestational bleeding and pregnancy outcome: a multivariable analysis. Int J Epidemiol. 1983;12:165-73.

8. Batzofin JH, Fielding WL, Friedman EA. Effect of vaginal bleeding in early pregnancy on outcome. Obstet Gynecol. 1984;63:515-8.

9. Hertz JB, Heisterberg L. The outcome of pregnancy after threatened abortion. Acta Obstet Gynecol San. 1985;64:151-6.

10. Williams MA, Mitten D, Leibermine E. Adverse infant outcome associated with first trimester vaginal bleeding. Obstet Gynecol. 1991;78:14-8.

11. Karim SA, Bakhtawar I, Butta AT, Jalil M. Effects of first and second trimester vaginal bleeding on pregnancy outcome. J Pak Med Assoc. 1998;48:40-2.

12. Fourn L, Takpara I, Zohoun T. Pregnancies complicated by haemorrhage and birth of low birth weight infants in cotonon (Bemin). Sante. 1994;4(6):407-11.

13. Arfa M, Abdul Fataeh M, Zeid HA. Outcome of pregnancies complicated by early vaginal bleeding. East Mediters Health J. 2000;6:457-64.

14. Mustafa G, Khurshid R, Mushtaq, Shamas I, Mir S. Pregnancy outcome of patients complicated by threatened abortion. Internet $\mathbf{J}$ Gynecol Obstet. 2009;(14):1-4.

15. Evrenos A, Güngör A, Gülerman C, Cosar E. Obstetric outcomes of patients with abortus imminens in the first trimester. Arch Gynecol Obstet. 2014;289(3):499-504.

16. Lykke JA, Dideriksen KL, Lidegaard O, LanghoffRoos J. First trimester vaginal bleeding and complications later in pregnancy. Obstet Gynecol. 2010;115(5):935-44.

17. Johns J, Jauniaux E. Threatened miscarriage as a predictor of obstetric outcome. Obstet Gynecol. 2006;107:845-50.

18. Hossain R, Harris T, Lohsoonthorn V, Williams M. Risk of preterm delivery in relation to vaginal 
bleeding in early pregnancy. Eur J Obstet Gynecol Reprod Bio. 2007;135(2):158-63.

19. Hackney DN, Glantz JC. Vaginal bleeding in early pregnancy and preterm birth: systematic review and analysis of heterogeneity. J Maternal-Fetal Neonatal Med. 2011;24(6):778-86.
Cite this article as: Rai P, Kumari G, Kumari K, Jaiswal D. Evaluation of perinatal outcome in women presented with first trimester vaginal bleeding: our experience. Int J Reprod Contracept Obstet Gynecol 2017;6:829-32. 